\title{
PERBEDAAN PENGARUH PIJAT DAUN PANDAN WANGI DAN AIR JAHE MERAH TERHADAP PENURUNAN SKALA NYERI PADA PASIEN REMATHOID ARTHRITIS
}

\author{
Novika Andora ${ }^{1}$, Richta Puspita Haryanti ${ }^{2}$ \\ 1.2 Program Studi Keperawatan, Fakultas Kesehatan, Universitas Mitra Indonesia, Jl. ZA. \\ Pagar Alam No.7, Gedong Meneng, Kec. Rajabasa, Kota Bandar Lampung, Lampung 40115, \\ E-mail : novika@umitra.ac.id
}

\begin{abstract}
Abstrak
Latar Belakang : Tanaman Daun pandan mempunyai kandungan kimia antara lain alkaloida, saponin, flavonoida, tanin, polifenol, dan zat warna. Pandan wangi merupakan salah satu tanaman yang potensial untuk menghasilkan minyak atsiri sebagai stimulan dan antispasmodik dan efektif terhadap sakit kepala, epilepsi, sebagai obat untuk sakit tenggorokan dan rematik. Kompres jahe merah merupakan salah satu kombinasi antara terapi hangat dan terapi relaksasi yang bermanfaat pada penderita nyeri sendi yang tidak memiliki efek samping. Selain itu jahe juga memiliki efek farmakologis yaitu rasa panas dan pedas dimana rasa panas ini dapat meredakan rasa nyeri, kaku dan spasme otot serta terjadinya vasodilatasi pembuluh darah. Tujuan penelitian ini adalah mengetahui Perbedaan Pengaruh Pemberian Daun Pandan Wangi dan Air Jahe Merah Terhadap Penurunan Skala Nyeri Pada Pasien Remathoid Arthritis. Metode : penelitian ini menggunakan jenis penelitian kuantitatif, rancangan praeksperimen dengan menggunakan rancanagan pendekatan two group pre post test design. Populasi dalam penelitian ini adalah seluruh pasien dengan arthritis rheumautoid di Puskesmas Simpur Bandar Lampung dengan sampel sebanyak 30 orang. Analisis data menggunakan uji t. Hasil : hasil analisis univariat diperoleh rata-rata skala nyeri sebelum diberi daun pandan wangi yaitu 5,95, setelah diberi kompres air rebusan batang serai hangat yaitu 3,65. Rata-rata skala nyeri sebelum diberi kompres air rebusan jahe merah yaitu 5,85, setelah diberikan air rebusan jahe merah yaitu 2,75. Hasil analisis bivariat diperoleh ada pengaruh pemberian daun pandan wangi terhadap skala nyeri reumathoid arthritis ( $p$-value $=0,001)$. Ada pengaruh pemberian air rebusan jahe merah terhadap skala nyeri reumathoid arthritis $(p$-value $=0,000)$. Kesimpulan : Ada perbedaan pemberian daun pandan wangi dan kompres air rebusan jahe merah terhadap skala nyeri reumathoid arthritis ( $p$-value $=0,022$ ).
\end{abstract}

Kata kunci : Daun pandan wangi, kompres air rebusan jahe merah, nyeri rheumatoid arthritis

Abstract

Introducion : Pandan leaf plants contain chemical compounds including alkaloids, saponins, flavonoids, tannins, polyphenols, and dyes. Pandanus is one of the plants that has the potential to produce essential oils as a stimulant and antispasmodic and is effective against headaches, epilepsy, as a remedy for sore throats and rheumatism. Red ginger compress is a combination of warm therapy and relaxation therapy that is useful for people with joint pain that has no side effects. In addition, ginger also has a pharmacological effect, namely a hot and spicy taste where this heat can relieve pain, stiffness and muscle spasms and the occurrence of vasodilation of blood vessels. The purpose of this study was to determine the difference in the effect of giving Wangi Pandan Leaves and Red Ginger Water on Reducing Pain Scale in Rheumatoid Arthritis Patients. Methods : This research method uses quantitative research, pre-experimental design using a two-group prepost-test design approach. The population in this study were all patients with rheumatoid arthritis at Simpur Bandar Lampung Health Center with a sample of 30 people. Data analysis using t test. Result : The results of univariate analysis obtained that the average pain scale before being given fragrant pandan leaves was 5.95, after being given a compress of warm lemongrass boiled water was 3.65. The average pain scale before being given a red ginger boiled water compress was 5.85, after being given red ginger boiled water was 2.75. The results of the bivariate analysis showed that there was an effect of giving fragrant pandan leaves on the rheumatoid arthritis pain scale ( $p$-value $=0.001)$. There is an effect of red ginger boiled water on the rheumatoid arthritis pain scale $(p$-value $=0.000)$. Conclusion : There is a difference between giving fragrant pandan leaves and red ginger boiled water compresses on the rheumatoid arthritis pain scale ( $p$-value $=0.022)$. Keywords : Fragrant pandan leaves, red ginger decoction compresses, rheumatoid arthritis pain 


\section{PENDAHULUAN}

World Health Organisation (WHO) melaporkan bahwa 20\%, penduduk dunia terserang penyakit arthritis rheumatoid. Dimana 5-10\% adalah mereka yang berusia 5-20 tahun dan 20\% mereka yang berusia 55 tahun (Wiyono, 2010). Lebih dari 355 juta orang di dunia ternyata menderita penyakit rematik. Itu berarti, setiap enam orang di dunia ini satu di antaranya adalah penyandang Reumatoid yang mana jumlah penduduk dunia tahun 2012 sebanyak kurang lebih 7 miliar jiwa. Diperkirakan angka ini terus meningkat hingga tahun 2025 dengan indikasi lebih dari 25\% akan mengalami kelumpuhan.

Prevalensi rhemathoid arthritis pada lansia berdasarkan diagnosis di Provinsi Lampung tahun 2019 meningkat dari tahun sebelumya dari 51,22\% menjadi $54,7 \%$, yaitu sebanyak 118.659 kasus. Sedangkan prevalensi rhemathoid arthritis pada lansia di Kota Bandar Lampung yaitu 57,4\%, yaitu sebanyak 34.632 kasus (Dinas Kesehatan Provinsi Lampung, 2018).

Gejala klinis remathoid artritis yaitu nyeri, maka tindakan keperawatan pada individu dengan nyeri sangatlah penting. Tanpa melihat sifat, pola, atau penyebab nyeri, jika nyeri tidak diatasi secara adekuat akan mempunyai efek yang dapat membahayakan diluar ketidak nyamanan yang ditimbulkan. Selain merasakan ketidak nyamanan dan mengganggu, nyeri akut yang tidak reda dapat mempengaruhi berbagai sistem tubuh, misalnya sistem pulmonari, kardiovaskuler, gastrointestinal, endokrin dan imunologi (Smeltzer \& Bare, 2013).
Penatalaksanaan nyeri rheumatoid arthritis dapat dilakukan dengan Pemberian kompres air rebusan batang serei hangat. Penggunaan bahan alam, baik sebagai obat maupun tujuan lain cenderung meningkat, terlebih dengan adanya pemikiran mengunakan obat alami serta krisis berkepanjangan yang mengakibatkan turunnya daya beli masyarakat. Indonesia sebagai negara tropis memiliki kekayaan tanaman obat. Salah satu tanaman yang dimanfaatkan untuk pengobatan tradisional adalah pandan wangi (Pandanus amaryllifolius Roxb). Pandan wangi terdapat hampir di seluruh Indonesia, terutama daerah tropis dan banyak ditanam di halaman atau di kebun (Margareth dan Abu, 2010).

Berdasarkan data register Puskesmas Simpur Bandar Lampung, bahwa reumathoid arthritis merupakan penyakit yang sering diderita lansia dengan urutan ke-2 setelah hipertensi. Jumlah kunjungan pasien penderita reumathoid arthritis pada tahun 2016 mencapai 238 orang, kemudian meningkat pada tahun 2018 menjadi 262 orang, dan kembali meningkat pada tahun 2019 menjadi 284 orang.

Selain farmakologis, tatalaksana nonfarmakologis seperti kompres air hangat, pemberian daun pandan wangi dan olive oil dan kompres air rebusan jahe merah menjadi pilihan lain dalam mengurangi skala nyeri.

Penggunaan daun pandan wangi dikarenakan kaya alkaloid, terpenoid, steroid, flavanoid dan saponin. Senyawasenyawa ini berpotensi sebagai antioksidan alami. Selain itu daun pandan wangi juga mengandung flavonoid yang kandungan didalamnya terkandung antiinflamasi (antiradang) (Hapsari, 2010). Minyak yang 
diperoleh dari daun pandan wangi dideskripsikan sebagai stimulan dan antispasmodik dan efektif terhadap sakit kepala, epilepsi, sebagai obat untuk sakit tenggorokan dan rematik (Marwat, 2012).

Kompres jahe merah merupakan salah satu kombinasi antara terapi hangat dan terapi relaksasi yang bermanfaat pada penderita nyeri sendi yang tidak memiliki efek samping. Jahe mengandung senyawa phenol yang terbukti memiliki efek anti radang dan diketahui ampuh mengusir penyakit sendi juga ketegangan yang dialami otot sehingga dapat memperbaiki system muskuloskeletal yang menurun. Selain itu jahe juga memiliki efek farmakologis yaitu rasa panas dan pedas dimana rasa panas ini dapat meredakan rasa nyeri, kaku dan spasme otot serta terjadinya vasodilatasi pembuluh darah (Susilowati, 2015).

Berdasarkan uraian masalah diatas maka, peneliti tertarik untuk melakukan penelitian tentang "Perbedaan Pengaruh Pemberian Daun Pandan Wangi dan Kompres Air Rebusan Jahe Merah Terhadap Penurunan Skala Nyeri Pada Pasien Remathoid Arthritis Di Puskesmas Simpur Bandar Lampung Tahun 2019”.

\section{METODE}

Jenis penelitian ini adalah kuantitatif, rancangan quasi eksperimen dengan menggunakan rancanagan pendekatan two group pre post test design. Populasi dalam penelitian ini adalah seluruh pasien dengan arthritis rheumautoid di Puskesmas Simpur Bandar Lampung dengan jumlah sampel sebanyak 40 orang. Teknik sampling yang digunakan dalam penelitian ini adalah simple random sampling dengan jumlah sample 30 orang. Variabel independen dalam penelitian ini yaitu kompres dengan air serai. Variabel dependen dalam penelitian ini adalah skala nyeri. Alat pengumpulan data pada penelitian ini adalah lembar observasi skala nyeri Numeric Rating Scale (NRS) dengan hasil pengukuran skala nyeri menggunakan NRS (skala 0-10), dipilih karena mudah dalam pengukurannya. Responden yang bersedia berparsisipasi kemudian dilakukan pretest dengan mengukur skala nyeri awal, kemudian pada kelompok pertama diberi pijatan daun pandan wangi yang dicampur dengan virgin coconut oil, dilakukan setiap nyeri muncul selama 20 menit dalam 7 hari berturut-turut, sedangkan untuk kelompok kedua, diberikan kompres rebusan air jahe merah setiap nyeri muncul selama 20 menit dalam 7 hari. Selanjutnya setelah mendapatkan perlakuan, pada kedua kelompok dilakukan posttest untuk mengetahui skala nyeri akhir. Analisis bivariat menggunakan analisis uji $\mathrm{T}$ (paired sample t-test). Tingkat kemaknaan yang digunakan dalam penelitian ini sebesar 0,05 .

\section{HASIL}

\section{Hasil Penelitian}

Analisis Univariat

a. Rata-Rata Skala Nyeri Sebelum dan Sesudah Diberi Pijat Daun Pandan wangi

Tabel 1.

Rata-Rata Skala Nyeri Sebelum dan Sesudah

\begin{tabular}{lllll}
\hline Variabel & Mean & Median & SD & $\begin{array}{l}\text { Minimum- } \\
\text { Maksimum }\end{array}$ \\
\hline $\begin{array}{l}\text { Skala } \\
\text { Nyeri } \\
\text { (pretest) }\end{array}$ & 5,95 & 6 & 1,461 & $3-8$ \\
\hline $\begin{array}{l}\text { Skala } \\
\text { Nyeri } \\
(\text { posttest })\end{array}$ & 3,65 & 3 & 1,638 & $0-6$ \\
\hline
\end{tabular}

Berdasarkan tabel 1.diperoleh bahwa ratarata skala nyeri sebelum diberi pijat daun 
pandan wangi pada kelompok intervensi yaitu 5,95. Sedangkan rata-rata skala nyeri setelah diberi pijat daun pandan wangi yaitu 3,65 .

\section{b. Rata-Rata Skala Nyeri Sebelum dan}

Sesudah Diberi Kompres Air

Rebusan Jahe Merah

Tabel 2.

Rata-Rata Skala Nyeri Sebelum dan Sesudah

\begin{tabular}{lcccc}
\hline Variabel & Mean & Median & SD & $\begin{array}{l}\text { Minimum- } \\
\text { Maksimum }\end{array}$ \\
\hline $\begin{array}{l}\text { Skala } \\
\begin{array}{l}\text { Nyeri } \\
\text { (pretest })\end{array}\end{array}$ & 5,85 & 6 & 1,309 & $3-8$ \\
\hline $\begin{array}{l}\text { Skala } \\
\text { Nyeri } \\
\text { (posttest })\end{array}$ & 2,75 & 4 & 1,609 & $0-5$ \\
\hline
\end{tabular}

Berdasarkan tabel 2.diperoleh bahwa ratarata skala nyeri sebelum diberi obat analgetik yaitu 5,85. Sedangkan rata-rata skala nyeri setelah diberi kompres air rebusan jahe merah yaitu 2,75.

\section{Analisis Bivariat}

a. Pengaruh Pemberian Pijat Daun Pandan Wangi Terhadap Skala Nyeri Reumathoid Arthritis

Tabel 3.

Efektivitas Pemberian Pijat Daun Pandan Wangi Terhadap Skala Nyeri Reumathoid Arthritis Pada Lansia

\begin{tabular}{lcclcl}
\multicolumn{6}{c}{ Arthritis Pada Lansia } \\
\hline Variabel & Mean & SD & $\begin{array}{l}\text { Mean } \\
\text { Different }\end{array}$ & SE & $\begin{array}{l}\text { P- } \\
\text { Value }\end{array}$ \\
\hline $\begin{array}{l}\text { Skala nyeri } \\
\text { (Pretest })\end{array}$ & 5,95 & 1,461 & & & \\
& & & 2,300 & 0,351 & 0,000
\end{tabular}

Skala nyeri $\quad 1,638$

(Posttest) $\quad 3,65$

Berdasarkan tabel 3. terlihat bahwa nilai rata-rata skala nyeri setelah pemberian pijat daun pandan wangi mengalami penurunan sebesar 2,4. Hasil uji statistik didapatkan nilai $p$-value $=0,000$, sehingga dapat disimpulkan bahwa ada pengaruh pemberian pijat daun pandan wangi terhadap skala nyeri reumathoid arthritis.

\section{b. Pengaruh Pemberian Kompres Air} Rebusan Jahe Merah Terhadap Skala Nyeri Reumathoid Arthritis Pada Lansia

Tabel 4.

Efektivitas Pemberian Kompres Air Jahe Merah Terhadap Skala Nyeri Reumathoid Arthritis Pada Lansia

\begin{tabular}{|c|c|c|c|c|c|}
\hline Variabel & Mean & SD & $\begin{array}{l}\text { Mean } \\
\text { Different }\end{array}$ & SE & $\begin{array}{l}\text { - } \\
\text { Value }\end{array}$ \\
\hline \multirow{2}{*}{$\begin{array}{l}\text { Skala } \\
\text { nyeri } \\
\text { (Pretest) }\end{array}$} & 5,85 & 1,309 & & & \\
\hline & & & 3,1 & 0,485 & 0,000 \\
\hline $\begin{array}{l}\text { Skala } \\
\text { nyeri } \\
\text { (Posttest) }\end{array}$ & 2,75 & 1,609 & & & \\
\hline
\end{tabular}

Berdasarkan tabel 4.terlihat bahwa nilai rata-rata skala nyeri setelah pemberian kompres air jahe merah mengalami penurunan sebesar 3,1. Hasil uji statistik didapatkan nilai $p$-value $=0,000$, sehingga dapat disimpulkan bahwa ada pengaruh pemberian kompres rebusan air jahe merah terhadap skala nyeri reumathoid arthritis pada lansia.

c. Perbedaan Pengaruh Pemberian Pijat Daun Pandan Wangi dan Kompres Air Rebusan Jahe Merah Terhadap Skala Nyeri Reumathoid Arthritis Pada Lansia 
Tabel 5.

Perbedaan Efektivitas Pemberian Daun Pandan Wangi dan Kompres Air Rebusan Jahe Merah Terhadap Skala Nyeri Reumathoid Arthritis Pada Lansia

\begin{tabular}{|c|c|c|c|c|c|c|}
\hline Variabel & Mean & SD & $\begin{array}{l}\text { Mean } \\
\text { Different }\end{array}$ & SE & $\begin{array}{l}P \\
\text { Value }\end{array}$ & $\mathbf{N}$ \\
\hline $\begin{array}{l}\text { Penurunan } \\
\text { skala nyeri } \\
\text { kelompok } \\
\text { intervensi }\end{array}$ & 2,300 & 0,826 & 0,700 & 0,134 & 0,022 & 30 \\
\hline $\begin{array}{l}\text { Penurunan } \\
\text { skala nyeri } \\
\text { kelompok } \\
\text { kontrol }\end{array}$ & 3,1 & 1,569 & & & & \\
\hline
\end{tabular}

Berdasarkan tabel 5. terlihat bahwa nilai rata-rata penurunan skala nyeri pada kelompok yang diberi pijat daun pandan wangi yaitu 2,3 dan kelompok yang diberi obat sebesar 3,1 dimana penurunan skala nyeri sedikit lebih besar pada kelompok Kompres Air Rebusan Jahe Merah. Hasil uji statistik didapatkan $p$-value $=0,022$, hal ini dapat disimpulkan bahwa ada perbedaan efektivitas pemberian pijat daun pandan wangi dan kompres air rebusan jahe merah terhadap skala nyeri reumathoid arthritis pada lansia.

\section{PEMBAHASAN}

\section{Pengaruh Pijat Daun Pandan Wangi}

Menurut pendapat peneliti, ratarata skala nyeri pada responden sebelum diberi perlakuan merupakan kondisi nyeri yang biasa dialami responden saat mengalami rhemathoid arthritis. Nyeri rhemathoid arthritis akan timbul akibat adanya peradangan atau inflamasi pada persendian. Nyeri yang dirasakan berbedabeda pada setiap responden dari nyeri ringan sampai berat dimana beberapa faktor dapat berpengaruh terhadap skala nyeri. Salah satu faktor antara lain adalah usia, dimana semakin tua usia seseorang maka semakin tahan terhadap nyeri. Selain itu persepsi nyeri juga dapat dipengaruhi oleh jenis kelamin dimana wanita lebih peka terhadap nyeri. Sedangkan skala nyeri pada responden setelah diberi perlakuan merupakan perubahan skala nyeri yang terjadi akibat adanya perlakuan massage dengan daun pandan wangi dan virgin olive oli sebagai pelumas nya, dimana pada penelitian ini skala nyeri mengalami penurunan sebesar 2,30.

Tanaman obat menurut Depkes RI yang tercantum dalam SK Menkes No.149 / SK Menkes IV / 1978 adalah tananam atau bagian tanaman yang digunakan sebagai bahan baku obat (prekursor), atau ekstrak tanaman yang dapat digunakan sebagai obat. Dari beberapa tanaman diatas, salah satu tanaman yang diduga juga dapat dijadikan sebagai obat kontrasepsi pria dan bersifat antifertilitas karena mempunyai kandungan zat yang sama seperti Saponin, tanin, flavanoid, alkaloid, polifenol dan zat warna adalah daun pandan wangi (Pandamus amaryllifolius Roxb) (Yuniarti, 2008).

Penggunaan daun pandan wangi dikarenakan kaya alkaloid, terpenoid, steroid, flavanoid dan saponin. Senyawasenyawa ini berpotensi sebagai antioksidan alami. Selain itu daun pandan wangi juga mengandung flavonoid yang kandungan didalamnya terkandung antiinflamasi (antiradang) (Hapsari, 2010). Minyak yang diperoleh dari daun pandan wangi dideskripsikan sebagai stimulan dan antispasmodik dan efektif terhadap sakit kepala, epilepsi, sebagai obat untuk sakit tenggorokan dan rematik (Rezza, 2014).

Berdasarkan penelitian Hanuraga (2013) tentang pengaruh pemberian daun pandan terhadap skala nyeri pada pasien reumatik Di Wilayah Kerja Puskesmas Sumber Agung Kecamatan Metro Kibang Kabupaten Lampung Timur Tahun 2013, menyebutkan bahwa sebelum diberikan 
pandan wangi rata-rata nyeri pasien adalah 8,30 dan setelah diberika pandan wangi menjadi 4,22. Berdasarkan uji statistik diketahui bahwa p-value 0,001 atau pvalue $<0,05$ yang artinya ada pengaruh pemberian daun pandan terhadap skala nyeri pada pasien reumatik Di Wilayah Kerja Puskesmas Sumber Agung Kecamatan Metro Kibang Kabupaten Lampung Timur Tahun 2013.

Beberapa kandungan yang ada pada daun pandan. Pandan wangi memiliki aroma yang khas pada daunnya. Komponen aroma dasar dari daun pandan wangi itu berasal dari senyawa kimia 2-acetyl-1pyrroline (ACPY) yang terdapat juga pada tanaman jasmin, hanya saja konsentrasi ACPY pada pandan wangi lebih tinggi dibandingkan dengan jasmin (Rezza, 2014).

Daun pandan mempunyai kandungan kimia antara lain alkaloida, saponin, flavonoida, tanin, polifenol, dan zat warna. Pandan wangi merupakan salah satu tanaman yang potensial untuk menghasilkan minyak atsiri sebagai stimulan dan antispasmodik dan efektif terhadap sakit kepala, epilepsi, sebagai obat untuk sakit tenggorokan dan rematik (Rohmawati E., 2012).

\section{Pengaruh Kompres Air Rebusan Jahe Merah}

Menurut pendapat peneliti, adanya pengaruh pemberian kompres air jahe merah terhadap penurunan skala nyeri remathoid arthritis pada lansia disebabkan karena beberapa kandungan yang terdapat pada jahe yang memiliki efek analgesik. Adapun efek analgesik kompres jahe berhubungan dengan unsur-unsur yang terkandung dalam jahe. Yang akan menghambat sikooksigenase sehingga terjadi penurunan pembentukan dari mediator peradangan (prostaglandin) yang menyebabkan berkurangnya rasa nyeri. Selain itu, efek panas yang ditimbulkan dari jahe memberikan efek relaksasi sekaligus distraksi sehingga akan mengurangi sensasi nyeri.

Hasil penelitian ini sesuai dengan teori yang dikemukakan oleh Brunner and Suddarth, dalam Damaiyanti (2012), cara untuk mengurangi nyeri pada penderita rhematoid artritis salah satunya adalah kompres jahe hangat, karena jahe memiliki kandungan enzim siklooksigenase yang dapat mengurangi peradangan pada penderita arthritis rhematoid, selain itu jahe juga memiliki efek rasa panas dan pedas, dimana dapat meredakan rasa nyeri, kaku, dan spasme otot. Menurut Hernani \& Winarti (2010) dalam Syafitri (2018), bahwa beberapa komponen kimia jahe, seperti gingerol, shogaol dan zingerone memberi efek farmakologi dan fisiologi seperti antioksidan, anti inflamasi, analgesik, antikarsinogenik. Kandungan air dan minyak tidak menguap pada jahe berfungsi sebagai enhancer yang dapat meningkatkan permeabilitas oleoresin menembus kulit tanpa menyebabkan iritasi atau kerusakan hingga ke sirkulasi perifer. Senyawa gingerol telah terbukti mempunyai aktivitas sebagai antipiretik, antitusif, hipotensif anti inflamasi dan analgesic.

\section{Perbedaan Pengaruh Pemberian Daun Pandan Wangi dan Kompres Rebusan} Air Jahe Terhadap Skala Nyeri Reumathoid Arthritis Pada Lansia

Berdasarkan hasil penelitian diperoleh bahwa ada perbedaan pengaruh pemberian kompres air rebusan batang serai hangat dan kompres air rebusan jahe merah terhadap skala nyeri reumathoid 
arthritis pada lansia ( $p$-value $=0,022)$. Meskipun perbedaan skala nyeri antara kedua kelompok tidaklah besar yaitu pada kelompok kompres air rebusan jahe merah menurunkan skala nyeri sebesar 3,1 dan kelompok pijat dengan daun pandan wangi menurunkan skala nyeri sebesar 2,3.

Menurut pendapat peneliti, air rebusan jahe merah hangat lebih menurunkan skala nyeri dibandingkan dengan yang diberi rebusan batang serai disebabkan karena selain memiliki efek analgesik kompres jahe berhubungan dengan unsur-unsur yang terkandung dalam jahe. Yang akan menghambat sikooksigenase sehingga terjadi penurunan pembentukan dari mediator peradangan (prostaglandin) yang menyebabkan berkurangnya rasa nyeri. Selain itu, efek panas yang ditimbulkan dari jahe lebih besar dibandingkan batang serai yang memberikan efek relaksasi sekaligus distraksi sehingga akan mengurangi sensasi nyeri.

Menurut Hernani \& Winarti (2010) dalam Syafitri (2018), bahwa beberapa komponen kimia jahe, seperti gingerol, shogaol dan zingerone memberi efek farmakologi dan fisiologi seperti antioksidan, anti inflamasi, analgesik, antikarsinogenik. Kandungan air dan minyak tidak menguap pada jahe berfungsi sebagai enhancer yang dapat meningkatkan permeabilitas oleoresin menembus kulit tanpa menyebabkan iritasi atau kerusakan hingga ke sirkulasi perifer. Senyawa gingerol telah terbukti mempunyai aktivitas sebagai antipiretik, antitusif, hipotensif anti inflamasi dan analgesic.

\section{KESIMPULAN}

1. Rata-rata skala nyeri sebelum diberi pijat daun pandan wangi yaitu 5,95 (skala nyeri sedang). Sedangkan ratarata skala nyeri setelah diberi pijat daun pandan wangi dengan virgin coconut oil adalah 3,65 (skala nyeri ringan).

2. Rata-rata skala nyeri sebelum diberi kompres air jahe merah yaitu 5,85 (skala nyeri sedang). Sedangkan ratarata skala nyeri setelah diberi obat analgetik yaitu 2,75 (skala nyeri ringan).

3. Kompres air jahe merah lebih menurunkan skala nyeri dibandingkan dengan pijat daun pandan wangi pada lansia dengan remathoid arthritis

\section{UCAPAN TERIMA KASIH}

Ucapan terima kasih kami ucapkan kepada Program Studi Keperawatan, Fakultas Kesehatan Universitas Mitra Indonesia, serta kepada pihak Puskesmas Simpur Bandar Lampung yang telah berkenan memberikan izin untuk melakukan penelitian.

\section{REFERENSI}

Chintyawati., 2014. Hubungan Nyeri Rhemathoid Arthritis Dengan

Kemandirian Dalam Aktivitas Kehidupan Sehari-Hari Pada Lansia di Posbindu Karang Mekar. Jurnal UIN Syarif Hidatyatullah.

Damaiyanti. 2012. Pengaruh Kompres Jahe Hangat Terhadap Penurunan Intensitas Nyeri Artritis Rhematoid Pada Lanjut Usia Di Panti Sosial Tresna Werdha Kasih Sayang Ibu Kanagarian Cubadak Batu Sangkar 2012. Jurnal. Tidak diterbitkan.

Dinas Kesehatan Provinsi Lampung. 2018. Profil Kesehatan Provinsi Lampung. 
Hasim. 2017. Perbedaan Pengaruh Kompres Jahe Merah Dan Kompres Hangat Terhadap Penurunan Skala Nyeri Sendi Pada Lanjut UsiaJurnal. Tidak diterbitkan.

Margareth, H. dan Abu Muhammad. 2010. Kamus Pintar Obat Herbal. Yogyakarta: Nuha Medika

Rezza Suherry dkk (2014). Tentang Pemberian Campuran Daun Pandan Wangi dan Virgin Coconut Oil Berpengaruh Terhadap Penurunan Nyeri Sendi pada Lansia dengan Osteoartritis di Puskesmas Mulyorejo Semarang Jurnal Penelitian (Diakses Tanggal 20 Januari 2018).

Smaltzer \& Bare., 2013. Buku Ajar Keperawatan Medical Bedah
Brunner \& Suddart. Edisi 8, Vol 1, alih Bahasa: Kuncara Monica Ester. Jakarta: EGC.

Susilowati. 2015. Pengaruh Pemberian Kompres Air Jahe Merah Dapat Mengurangi NyeriReumatoid Artritis. Jurnal. Tidak diterbitkan.

Syapitri, Henny. 2018.Kompres Jahe Berkhasiat Dalam Menurunkan Intensitas Nyeri Pada Penderita Rheumathoid ArthritisJurnal. Tidak diterbitkan.

Wibawa, Putu Gede S., 2016. Penatalaksanaan terkini Artritis Reumatoiddengan paradigma baru Treat-to-Target. Jurnal FK UNUD. WHO. 2013. Prevalensi Kejadian Rematik. USA: Philadelphi. 